\title{
Thirty - Six Stratagems and Business Negotiation Theories
}

\author{
Chen Haiwei, Shi Yeli \\ Zhejiang Ocean University, Zhoushan, China
}

\begin{abstract}
With the deepening of economic globalization and the internationalization of trade, the international trade activities are becoming more and more frequent, and the role of the business negotiation is more prominent. Under the unremitting efforts, the domestic and foreign scholars summed up some major theories of business negotiations, and enriched the systematic and theoretical process of business negotiation knowledge. Meanwhile, the thirty-six stratagems are the essence of Chinese art of war, containing so many unique psychological skills. The combination of the business negotiation theories with thirty-six stratagems will be conducive to the flexible use of negotiating skills, provide more help for business negotiators to adapt to an increasingly complex economic situation.
\end{abstract}

Keywords: thirty-six stratagems, business negotiation, and negotiation theory

\section{INTRODUCTION}

In today's society, negotiations are everywhere and always play an important role — not only in the bargains of shopping, but also in the international trades. Negotiations can be understood as both parties to achieve their own interests, through communication or consultation to achieve a consistent process of action. (Wang, 2010) Nowadays, with the further development of economic globalization and trade liberalization, the role of business negotiation has become increasingly prominent in the international economic and trade activities, which triggered the systematic and theoretical study on the process of business negotiation, especially negotiation skills. Domestic and foreign scholars have integrated a large number of business negotiation knowledge and summed up some major business theories of business negotiation the Maslow's hierarchy of needs, the Equity Theory, the Collaborative Principled theory, the black-box theory, the game theory and so on. Such theoretical knowledge is beneficial to business negotiations and is likely to increase benefits.

In addition, from the nature of speaking, a negotiation is a process of interaction with people. In this process, people often need to use different strategies and techniques to obtain greater benefits or achieve a win-win situation, which is the final goal. The strategies frequently used in negotiations coincide with the thirty-six stratagems of the Chinese art of war (Chen \& Kong, 2006).The so-called thirty-six stratagems contain the laws of war and flexible use of strategies, which can help negotiators occupy a favorable position in negotiations, and eventually win the negotiations.

In order to promote the further development and innovation of business negotiations, it is workable to combine the above five systematic theories of business negotiation with the "thirty-six stratagems" that is the essence of the Chinese art of war, which will definitely deepen the negotiation skills and provide more favorable weapons for business negotiators.

\section{Five Main Stratagems and Business Negotiation TheOries}

\subsection{The Stratagem of Tossing out a Brick to Get a Jade Gem and the Maslow'S Hierarchy of Need Theory}

The stratagem of "Tossing out a brick to get a jade gem" is that "Bait someone by making him believe he gains something or just make him react to it ('toss out a brick') and obtain something valuable from him in return ('get a jade gem') ". It can be understood as "to attract the opponent with similar but smaller interests". (China's Foreign Trade, 2012) Then people could gradually explore others' needs and their bottom line to make them stand at an advantage, so as to gain more profits by giving little. This is similar to the theory of "the Maslow's hierarchy of needs" from western countries, which is mainly about the understanding of human motivation and their personal development. 
In1954, Maslow put forward the Hierarchy of Needs and pointed out the five stage model---biological and physiological needs, safety needs, love and sense of belonging needs, esteem needs and selfactualization needs. Then in 1970, he expanded these state models to cognitive and aesthetic needs and later transcendence needs. Under the context of today's economy, the essential needs in negotiations are definitely mental needs and beneficial needs (Yuan, 2014). Infact, the mental needs are interpreted as getting enough attention or respect from others, especially when the two sides are from different countries and have different customs. For the beneficial needs, it means to get more profits for themselves. Therefore, in order to win the negotiation, people need to respect the opposite side and satisfy their needs in some aspects when insisting on the basic target and needs of themselves. Thus, it will be useful to link the stratagem of toss in gout a brick to get a jadegem with the theory of Maslow's hierarchy of needs to win the negotiations.

For example, Mike once went to Germany to buy a coal mine as the representative of a company. The owner of the mine was a tough negotiator and he offered a price of 26 million dollars. Mike made a bargain of 15 million dollars but the owner insisted on his price. Therefore, it was so difficult for them to continue to negotiate. In the next few months, Mike put up his price to 21.5 million dollars. However, the owner still persisted in his former price rather than make any concessions. It meant that the negotiation was at a deadlock. But Mike did not give up even if the situation was so embarrassing and he tried his best to find the true reason why the owner insisted on such a high price all the time. After that, he tried to make more communication with the owner and sincerely invited him to play tennis together. Finally, the owner was moved by Mike' sun remitting efforts and told Mike his true purpose. In fact, his brother had sold his coal mine for 25 million dollars with some additional conditions. In this way, Mike had remembered that the owner was just eager to compare with his brother and even to surpass him. This is the real need of the owner. By understanding that, Mike quickly made a research about the price and its additional conditions from his brother, and then put forward a new negotiation scheme to satisfy his needs. Meanwhile, the owner also made some concessions, which promoted the process of this negotiation. Finally, Mike and the owner of the coalmine reached an agreement that the price was not beyond the budget for Mike and the payment and additional conditions satisfied the needs of the owner to surpass his brother. It is a win-win negotiation (Jiang \& Zhang, 2006).

This case shows us that people will not cooperate with you when you have not given them what they want and need. Consequently, the negotiation will fail. Thus, in order to succeed in negotiations, you'd better find and understand the real needs between achother, and settle different standards for different needs so as to satisfy their respective needs. Once their needs are met, they will make certain concessions to what you need. This is the quintessence of the stratagem of "tossing out a brick to get a jadegem".

\subsection{The Stratagem of "Sacrifice the Plum Tree to Preserve the Peach Tree" and the Equity Theory}

The stratagem of "Sacrifice the plum tree to preserve the peach tree" is that "Castaway the minor for the major. There are circumstances in which you must sacrifice short-term objectives in order to gain the long-term goal. This is the scapegoat stratagem where by some one else suffers the consequences so that the rest do not. "(China's Foreign Trade, 2012) It means that you need to sacrifice partial profit to satisfy the needs of the other side in the negotiations when your loss is in escapable. In this way, you succeed in satisfying their mental sense of achievement so that they may make some concession in the aspects where you would value more. After all, there exists the possibility of difference in beneficial target for two sides. If that is the case, it will be a win-win negotiation. However, stalemates always occur in business negotiations due to the fact that both sides stick to a firm stand and reject any concessions. In this case, in order to get out of the stalemate and gain the target profit, people could employ the stratagem of "sacrificing the plum tree to preserve the peach tree". That is "to retreat in order to advance". Retreating is a signal of sincerity, a gesture of reciprocity, which is in accordance with the Equity Theory.

The Equity theory focuses on determining whether the distribution of resources is fair to both relational partners. Equity is measured by comparing the ratio of contributions (or costs) and benefits (or rewards) for each person. It embodies human's motivation for keeping fairness and their feelings of equity. In contrast, when equity cannot be maintained, in other words, the ratio of inputs to outcomes is out of expectation, feelings of inequity arise. (Ryan, 2016:1588) In business negotiations, the equity theory can be explained as the expectation on the negotiation result and the gained profit. 
When one party retreats, the other will make corresponding concession based on the equity theory. The application of this theory may generates various possibilities in business negotiation and leads to the expected target or accomplishment. And the stratagem of "sacrificing the plum tree to preserve the peach tree" is a good demonstration of the theory and a useful guideline for business negotiators. The following case is a powerful proof.

Years ago, in the negotiation of China's entry into WTO with the USA, Premier Zhu Rongji retrieved the nearly broken situation through his in-person participation and his efforts in the negotiation and finally reached an agreement. In this case, he just combined the stratagem of "sacrificing the plum tree to preserve the peach tree" with the Equity Theory. The vice-minister Long Yongtu could still well remember about that. He said, "On November 15th, 1999, when the negotiation was almost broken, the Premier Zhu personally participated in the negotiation and he figured out seven knotty problems to negotiate with the USA again. Premiers participation meant, to some extent, no retreat for China, for Zhu was a decision maker. However, there was no better choice under such an urgent situation. Finally, it was the premier Zhu, together with his other team members, who on behalf of China negotiated with the three representatives from the USA. Nevertheless, at the right beginning of the negotiation, premier Zhu made a concession in the first problem of sevens. Then, I worried about it and furtively wrote a note to him, but he just ignored and made concessions again in the second problem. I felt so anxious that I wrote another note to him. But Mr Zhu just told me not to write it again and spoke to the American representatives that "We have made concessions in these two problems and it is our bottom line. "e The American representatives were obviously surprised at the presence of the premier Zhu and our concessions, and they finally reached an agreement with us through serious discussions. "On November 15th, 1999, Sino-US finally reached a bilateral agreement and achieved a win-win negotiation. It successfully removed the major barriers in China's entry into the WTO. On November 10th, 2001, the Fourth Ministerial Conference of the World Trade Organization (WTO) in Doha, Qatar witnessed China's final success. (The Friends of Farm, 2012)

In this case, it is obvious that the negotiation was in trouble, but the entry into the WTO was essential and meaningful for China, which meant certain concession should be made in the negotiation. However, the national interest was of ultimate importance and could not be hurt even if China were in a weaker position. So it was difficult to decide the degree of concessions. In the above negotiation, premier Zhu made some concessions in the first two problems to ease its serious atmosphere and mean while to show the sincerity by sacrificing partial interest, so as to win the trust from the USA and their concessions in China's entry into the WTO. Finally, he succeeded in negotiating. There is no doubt that on some occasions making concessions is not equivalent to loss in negotiations but a strategy to success. Sacrificing some profits may help win other's trust and certain concessions that you want, which is verified by the above case. The case is still instructive to today's business negotiations. Therefore, mastery of the strategy of combining the stratagem of "sacrificing the plum tree to preserve the peach tree" with the Equity Theory will surely lead to huge progress in negotiating skills.

\subsection{The Stratagem of Defeating the Enemy by Capturing their Chief and the Collaborative Principled Theory}

The stratagem of "Defeating the enemy by capturing their chief" is that "If the enemy's army is strong but allied to the commander at the mercy of money, superstition or threats, then take aim at the leader. If the commander is captured or killed, the army will break up or surrender. However, if, they are allied to the leader through loyalty then beware, the army can continue to fight on after his death out of vengeance."'(China's Foreign Trade, 2012) Although this stratagem was adopted for eliminating the main enemy force in ancient, nowadays, it can be interpreted as catching the key point of problems to make double achievements with half the effort.

In business negotiations, there are often negotiation deadlock caused by the issue of standpoint or the personal emotional problems between the two sides. These problems mostly are the result of going against the Collaborative Principled theory. The Collaborative Principled theory has four principles abbreviated as PIOC (People, Interest, Option, Criteria): separate people from the problem; focus on interests, not position; invest options for mutual gains; insist on using objective criteria. (Liu, Wang \& Zhang, 2011) Infact, it is a little similar to the hierarchy of needs theory and the collaborative principled theory, for the needs of others should be realized. But the latter pays more attention to the trans-positional consideration. It always speculates on the other's needs. Stand in their shoes, respect 
and attach great importance to their advice, and then find a win-win collaborative scheme with consideration of different interest rather than misunderstanding each other in negotiations. The gist of the theory is consistent with the former stratagem of defeating the enemy by capturing their chief, for the focus of negotiations is always the benefit and its distribution between the concerned sides. However, the key benefit may vary with concrete situations. Thus, each one need to make great preparation in advance and take actions accordingly.

For example, if there is a sporting goods company named A from the USA; and another sporting goods company named B from China. Company A wants to enlarge its market and improve its reputation in China. Meanwhile the company B is eager to strengthen its power by importing advanced technology. Therefore, they can easily know their key benefits are different which means there will be a great possibility to cooperate between company A and B. In the negotiation, priority should be given to the respective key benefits and profits rather than different negotiation styles or frictions out of cultural difference with a view to gaining mutual trust. Only in this way can they achieve a win-win negotiation. In fact, on the one hand, business is a war and rivals are unlikely to be always in rapport, thus people need to be on alert. On the other hand, there will always be possible to cooperate for great benefits, even if they are competitors, for cooperation brings in more profits and benefits all concerned sides.

\subsection{The Stratagem of "Decking the Tree with False Blossoms" and the Black-Box Theory}

The stratagem of "decking the tree with false blossoms" is "tying silk blossoms on a dead tree gives the illusion that the tree is healthy. Through the use of artifice and disguise, make something valueless appear valuable; in formidable appear formidable; useless appear useful."(China's Foreign Trade, 2012) The present meaning is that when one side is at a disadvantage, he could make full use of objective environment and situation to confuse others and intercept their further aggression. And then try his best to find new ways to break through.

The Black-box theory comes from cybernetics, founded by American scientist Norbert Wiener. In cybernetics, the "white-box" refers to the whole area, and the "black-box" refers to the unknown area, where people need to explore industriously. However, the "black-box" cannot be opened, and people can only find and summarize its laws by observing its "input" and "output" situation, aiming at the understanding and control of the "black-box". (Liu, 2006) In business negotiations, our aim is to reduce the black-box field and expand the white-box field through various strategies and techniques to constrain the uncertainties caused by the black-box field and to form a favorable negotiation situation. These strategies include decking the tree with false blossoms.

An experienced negotiator once represented his client to discuss claims with sales staff from an insurance company. He did not know very well how much the insurance company could compensate, which is what we usually think the "blackbox". So the negotiator decided to speak less and make more observation without any expression. The insurance actuary claimed that "Sir, as usual for this kind of situation, we can only compensate $\$ 100$, how do you think?" The negotiator kept a serious expression without any words. Silent for a while, the actuary said, "How about adding $\$ 100$ ?" Negotiator continued to keep silent and after a longtime, he said that "Sorry, we cannot accept that."The insurance actuary continued to say "Well, then add \$100 again." Negotiator did not speak, then shook his head. The actuary seemed to be in a panic, "It would be $\$ 400$ ?" Negotiator still did not speak, but obviously not satisfied with the amount. The actuary had to say "How about \$ 500?" But negotiator repeated his silence, so the actuary had to continue to increase his indemnity. The final result of the negotiation was that the insurance company compensated 950USdollars, which greatly exceeded $\$ 300$ expected by his client. (Liu, 2006) It is just a common case in our life. And in this case, the reason why the negotiator could be the winner of the negotiation was that he mastered the principle of "Black-box" theory. Here the compensation ceiling was the "black box", and the negotiator was in a favorable position as the claimer. The "black box" theory is rather similar to Chinese stratagem of "decking the tree with false blossoms". Because the actuary did not know the targeted amount of money, the negotiator could hold a silent attitude to confuse the opponent and exert pressure on him, to force him to make certain concessions and transform the "black box" into "White box" so as to get more benefits than expected. However, the upper limit of benefit cannot be crossed. Otherwise, it is not a rational negotiation but rather a black mail, an embodiment of greediness. It is also a gateway to failure or dead end. 


\subsection{The Stratagem of "Befriending a Distant State while Attacking a Neighbor" and the Game Theory}

"Befriending a distant state while attacking a neighbor" means that "It is known that bordering nations may become enemies while distant nations may become allies".(China's Foreign Trade, 2012) Similarly, the threat for the strongest in one field is from these $\mathrm{c}$ on $\mathrm{d}$ to it, not the strongest from another field. This stratagem can also be applied in the competitive business world. It is a wise strategy to prevent opponents from cooperating with other leading companies and take an early step to contact and negotiate with those leading companies far away in advance and endeavor to build a friendly relationship with them. In this way, what the company get is not only a new business friend who may not threaten its subsistence and development because of their considerable distance, but also a strong assistancetodefeatthecompetitors.Nodoubtbothsideswillgetgreatbenefitforthemselves. Thevital point is to reach an agreement through awareness of the promising prospect and profits in the future cooperation and by compromise in the negotiations.

Meanwhile, the game theory is widely used around the world in negotiations. Simply put, the game theory means to play a game and make negotiations aiming at the benefit problems on the basis of cooperative purpose between each other. From the equilibrium outcome of the game, the game is divided into cooperative and non-cooperative game. Cooperative game is to choose the cooperation that is beneficial to the game participants from their own interests, rather than the choice of damaging at least one side of the game participants in the cooperative game results, such as the prisoner's dilemma.(Yuan, 2014) Business negotiations are mostly cooperative game, where each participant can be benefited. Thus the key point is the distribution of interest. During the process of games, there are so many stratagems from the six-thirty stratagems can be utilized, especially the stratagem of "befriending a distant state while attacking a neighbor". The integrated employment of this stratagem with the game theory in negations may produce an unexpected outcome.

For instance, there are two car corporations named C and D respectively in a same city. They are fierce competitors in the car market. The company $\mathrm{C}$ has the advantage of lower price, but $\mathrm{D}$ is good at its fashionable appearance and higher quality so that $\mathrm{D}$ has occupied the bigger market. In this case, in order to improve its competitiveness, the company $\mathrm{C}$ can utilize the stratagem of "befriending a distant state while attacking a neighbor" to cooperate with a high-quality brand company from another first-tier cities such as the company E. It can attract their eyes through its large car market and make proper concession in benefit so as to win their trust and technological support to enhance the company's ability and its competitiveness. In this way, with the help of the company E and its great brand reputation, the company $\mathrm{C}$ will gradually occupy a larger market and get more profits. This shows the cooperative game between the company $\mathrm{C}$ and $\mathrm{D}$. And it is also an usual situation of cooperative game. Alternatively, the company $\mathrm{C}$ can also choose to cooperate with $\mathrm{D}$ and combine the advantages from each other, occupy the whole car market in their city and make more profits. This is another situation of cooperative game. All in all, finding a reliable partner is a great way to defeat your competitors in the market.

\section{The Other Four Classical Stratagems in The Commercial War}

In addition to the above stratagems, other strategies from the thirty-six stratagems can also play a key role in business negotiations. First is "the beauty trap". (China's Foreign Trade, 2012) It is so called in that everyone has their love for the beauty from the bottom of heart. In some cases, dispatching the good-looking people to negotiate with others will produce a better effect on distracting the attention of competitors or alleviating the aggressive atmosphere. Second is "inflicting injury on one self to win the enemy's trust". (China's Foreign Trade, 2012) Generally speaking, everyone has compassion. Therefore, when people are in a disadvantage condition or fail to get other's trust in the negotiations, they can trigger their compassion through the self-harm approaches, so as to obtain mutual trust. On this basis, they will have a greater chance to fight for a relatively high interest. Third are "Enticing the tiger to leave its mountain lair" (China's Foreign Trade, 2012) and "Making the host and the guest exchange roles" (China's Foreign Trade, 2012). The venue for negotiations should be placed in the environment we are familiar with, so that we will occupy the home advantage and convert the passive to initiative. Fourth is "Hiding a knife behind a smile". (China's Foreign Trade, 2012) In business negotiations, no matter what the situation people meet, they should keep smiling to show their composure and confidence. Meanwhile, they'd better hold a tough attitude rather than be oppressed by the deterrence from the competitors, and always take the initiative, step by step, to win the negotiations. 


\section{Conclusion}

Under the background of increasingly frequent economic and trade activities in the world, the role and status of business negotiations have been more prominent. And a business negotiation is not just the verbal communication, but also the psychological game and confrontation. The Thirty- six stratagems as the heritage of the Chinese civilization and the essence of Chinese art of war, even in the everchanging today, its flexible tactical use and calm psychological attack and defense still has important guidance and reference for international business negotiation under the background of economic globalization. Therefore, integrating Chinese ancient stratagems into such negotiation theories is conducive to modern business as the Maslow's hierarchy of needs, the Equity theory, the Collaborative Principled Negotiation, the black-box theory, the game theory and so on, which opens a new window for the flexible use of business negotiation skills in the increasingly complex environment of negotiations in new times. For business negotiators, further understanding of the thirty six stratagems will help them grasp more strategies and skills, enabling them to gain the upper hand in negotiations and cope with all kinds of potential risks. Eventually, they will be the ultimate beneficiaries.

\section{REFERENCES}

[1] Wang, H. L. (2010) Business Negotiation. Beijing: The publishing company of Economic and Management

[2] Chen,C. J.\& Kong, M.Q. (2006) The complete works of thirty-six stratagems. Beijing: The Tides Press

[3] China's Foreign Trade.(2012) The Thirty-Six Stratagems( I ). China's Foreign Trade. No 6:9495

[4] Yuan, Q. G. (2014) Business Negotiation. Beijing: The Electronic Industry Press

[5] Jiang, S. G. \& Zhang, H.(2006) Business Negotiation. Beijing: The Capital University of Economics and Business Press

[6] Ryan, J. C. (2016) Old knowledge for new impacts Equity theory and work force nationalization. Journal of Business Research. Vol. 69(5): 1587-1592

[7] The Friends of Farm.(2012) Long Yong-tu disclose the key details of China's entry into WTO negotiations. The Friends of Farm. No 1: 30-31

[8] Liu,B. Y, Wang, M. L.\& Zhang, Y. L.(2011) International Business Negotiation. Beijing: The Renmin University of China Press

[9] China's Foreign Trade.(2012)The Thirty-Six Stratagems( II ).China's Foreign Trade. No 7:9495

[10] Liu, Z.C. (2006) Business Negotiation. Guangzhou: The Guang-dong Higher Education Press

\section{AUTHORS' BiograPhy}

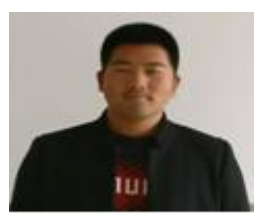

Haiwei, Chen, China, was born on May 17, 1996. He is a junior of Foreign Language College, Zhejiang Ocean University, majoring in business English

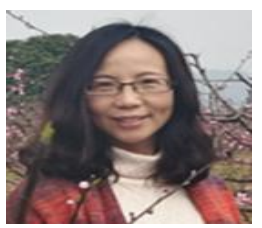

Yeli, Shi, Associate Professor of Foreign Language College, Zhejiang Ocean University, China. Master of Arts in Literature and Language, Zhejiang University. Research area: cross-culture communication, metaphor, and business English teaching. 